\title{
Pulmonary metastasectomy in germ cell tumors and prostate cancer
}

\author{
Federico Raveglia ${ }^{1}$, Lorenzo Rosso ${ }^{2}$, Mario Nosotti ${ }^{2}$, Giuseppe Cardillo ${ }^{3}$, Gabrielle Maffeis ${ }^{4}$, Marco \\ Scarci $^{4}$
}

${ }^{1}$ Thoracic Surgery, ASST Santi Paolo e Carlo, Ospedale San Paolo, Milano, Italy; ${ }^{2}$ Department of Thoracic Surgery, Fondazione IRCCS Ca' Granda Ospedale Maggiore Policlinico, Università degli Studi di Milano, Milano, Italy; ${ }^{3}$ Department of Thoracic Surgery, Azienda Ospedaliera S. Camillo Forlanini, Rome, Italy; ${ }^{4}$ Department of Thoracic Surgery, ASST Monza e Brianza, Ospedale San Gerardo, Monza, Italy

Contributions: (I) Conception and design: F Raveglia, M Scarci; (II) Administrative support: M Scarci; (III) Provision of study materials or patients: L Rosso; (IV) Collection and assembly of data: M Nosotti; (V) Data analysis and interpretation: All authors; (VI) Manuscript writing: All author; (VII) Final approval of manuscript: All authors.

Correspondence to: Federico Raveglia. ASST Santi Paolo e Carlo, Via di Rudinì 8, 20142 Milano, Italy. Email: federico.raveglia@asst-santipaolocarlo.it.

\begin{abstract}
Pulmonary oligo-metastases and oligo-recurrences are terms used to define a set of clinical conditions consisting of limited metastatic malignant disease characterized by an intermediate aggressive behavior compared to diffuse metastatic conditions. If the primary tumor has been controlled and extrathoracic lesions are excluded, there is a suggestion in the medical literature that removal of such lesions could potentially prolong survival. The lungs are a common metastatic spreading site, especially from epithelial malignancies and sarcomas; pulmonary surgical or interventional metastasectomy have been proposed with curative intent in case of limited tumor load (usually less than 5 lesions). There are many series reporting data about colorectal, renal or breast lung metastasectomy, but the absence of multi centric prospective trials determines a lack of definitive evidence, especially for less common tumors such as metastatic germ cell and prostate cancer. They rarely present in the oligo-metastatic form and their management is often based on personal experience. The aim of our article is to review the latest evidence in the treatment of pulmonary metastatic germ cell and prostate tumors. We cover the full range of treatments: from surgery to ablative radiotherapy and combination of local and systemic therapy. Despite the absence of evidence based guidelines, it emerges that pulmonary metastasectomy should always be considered when general criteria for resection have been met. In germ cell tumors surgery should be mainly reserved for residual disease after chemotherapy, whereas in prostate cancer, pulmonary metastasectomy should be preferred to avoid or delay hormonal deprivation therapy and its side effects.
\end{abstract}

Keywords: Metastasectomy; pulmonary; germ cell tumor; prostate cancer

Submitted Dec 12, 2019. Accepted for publication Apr 02, 2020.

doi: $10.21037 /$ jtd.2020.04.51

View this article at: http://dx.doi.org/10.21037/jtd.2020.04.51

\section{Introduction}

Metastatic cancer is usually associated with aggressive behavior with poor prognosis and, usually, patients are referred for palliative treatments. In case of oligo-metastatic stage, that is a limited number of metastatic lesions, it might be appropriate to postulate a less aggressive behavior with better outcomes (1). In these, selected sub-group surgery is progressively assuming the new role of potential curative treatment, if all sites of metastasis could be controlled.

In 1997, a long-term prognostic analysis on 5,206 lung metastasectomies showed that survival after complete resection was $36 \%, 26 \%$ and $22 \%$ at 5,10 and 15 years respectively with a median survival of 35 months. Based on these results, surgical resection for pulmonary metastasis has been commonly introduced in thoracic surgery. 
According to the International Registry of Lung Metastasis report, the most represented histology is epithelial (43\%) and sarcomatoid (42\%) tumors, whereas germ cell and malignant melanoma are respectively $7 \%$ and $6 \%$ of the other cases.

Since each histological type behaves differently, it is reasonable to assume that the efficacy and role of surgery depend on the primary tumor histology. Specifically, PM impact on survival in advanced germs cells and prostate tumors is still unclear and the absence of updated evidencebased guidelines often determines their management to rely on personal experience only. In 2019, the Society of Thoracic Surgeons (STS) Work Force of Evidence Based Surgery established a panel including experts in thoracic surgery, medical, and radiation oncology, in order to develop an STS expert consensus on PM (2). They decided that some general criteria should be always observed before referring patients to metastasectomy. The most important are: (I) primary cancer control, (II) absence of other extrathoracic metastasis and (III) complete metastasis resection. In addiction LN involvement, DFI, number of metastasis and laterality are also influencing points (3). Building up on these basic rules, we will deal specifically with germ cell and prostate tumor metastasis.

\section{Germ cell tumors (GCTs)}

GCTs are malignancies originating from reproductive cells with either malignant or benign behavior. Germ cells are usually found in the gonads (ovaries and testis). However, they can also be located in other parts of the body (such as: pineal gland, brain, mediastinum, or abdomen) in case of birth defects resulting from errors during development.

GCTs are histologically classified in two types, regardless of body location. There are the germinomas germ-cell tumors (GGCT), that includes only germinoma and the non-germinomas germ-cell tumors (NGGCT) including all others.

This classification is based on their clinical behavior. On one hand, NGGCTs are more likely to grow fast, affect younger patients, and present a lower 5 -year survival rate. NGGCTs comprehend embryonal carcinoma, teratocarcinoma, choriocarcinoma and yolk sac tumors. These are characterized by a strong propensity to disseminate, especially to the lungs (4). On the other hand, germinomas tumors present a better survival rate due to their intrinsic sensitivity to radiation and chemotherapy.

Testicular carcinoma is the most frequent malignant disease in young people aged between 15- and 35-yearold (5). Careful staging, timely systemic therapy and strict follow-up represent key points for successful outcomes. Unfortunately, though, metastatic spreading is possible even in early stages with about $8 \%$ of stage I cases developing lung metastases.

In advanced disease, lung, liver, brain and bones are the most common sites of spreading. Metastases can occur as late recurrences after a disease-free interval (DFI) or as chemotherapy-resistant synchronous disease. Their management is based on combination of chemotherapy and radiotherapy whilst surgery should be considered only for residual disease.

Tumor re-staging is performed by PET scan in association with serum tumor markers measurement (STMs). At present, available STMs are alpha-fetoprotein and beta-human chorionic gonadotropin. They are used during diagnosis but also in the management of advanced disease. Indeed, response to chemotherapy should be confirmed by imaging and STMs reduction. Nevertheless, in spite of the fact that about $54 \%$ to $71 \%$ of cases with residual disease and STMs normalization have complete necrosis or fibrosis in residual pulmonary masses (6), those could be composed by undifferentiated tumor with viable cancer, even with normal STMs.

In light of those considerations, the introduction of a multimodality approach (chemotherapy with surgery) in the management of advanced disease improved 5-year survival from $30 \%$ in the 1960 s to $90 \%$ from early 1980 s (7).

\section{Surgery}

Metastasectomy, with particular references to pulmonary metastasis, has been introduced from the early 1970s. It should be reserved to patients who present residual disease after chemotherapy. Indeed, chemotherapy is the gold standard also for advanced cases and achieves the best outcomes. However about $20-30 \%$ of subjects whose undergo systemic therapy for germ cell metastasis present residual disease $(8,9)$.

Outcomes after PM in germ cell tumors in terms of survival are very encouraging with a 5 -year OS ranging from $42 \%$ to $95 \%(10-12)$, but results are strictly conditioned by selection criteria. These are obviously consistent with general criteria for PM (complete resection, control of primary tumor, absence of extra-thoracic disease, long DFI) with some more peculiarities due to tumor histology.

According to the European Germ Cell Cancer 
Consensus Group (EGCCCG) PM is recommended after completed standard chemotherapy with cisplatin and serum markers normalization (13). Metastasectomy is, traditionally therefore, reserved for completion therapy for residual thoracic disease, in a multimodality fashion.

Further indications have been proposed over time broadening this practice. Different authors advocate pulmonary metastasectomy also in case of partial or absence of response to chemotherapy with palliative purpose in case of large necrotic or infected tumors or with diagnostic purpose when tumor nature needed to be confirmed or when viable tumor should be identified (14). Multiple pulmonary metastases, persistent elevated STMs or repeated PM have not been excluded either $(15,16)$. Furthermore, despite some articles reported better outcomes in case of single metastasis, there is no evidence that the number of nodules negatively affect prognosis.

Similarly, bilateral disease should not be a contraindication either. Indeed, several authors have shown that tumor histology is often different in the two lungs, confirming the need of bilateral approach to achieve radicality $(12,17)$.

Generally speaking, PM must be performed as soon as possible after diagnosis. In GCTs, since chemotherapy is the gold standard, surgery should be instead planned after systemic therapy. In order to avoid or reduce chemotherapyinduced complications, it has been suggested a rest time of 3-6 weeks (17-19).

Correct surgical approach for PM in GCTs is unclear, since most of available studies are focused on PM in general. VATS advantages are less postoperative pain and earlier patient recovery, whereas open surgery allows parenchymal bi-manual palpation with even small nodule detection $(18,20)$. In favor of VATS, Margaritora et al. (21) have pointed out that modern CT scan provides nodule detection even in $6 \mathrm{~mm}$ lesions making manual palpation often not useful or even less effective. At the same, Boffa et al. (18) showed that GCTs lung metastasis are often peripheral and small, suggesting successful parenchyma evaluation with VATS as well.

Open surgery is probably more frequent, as reported by Farazdaghi et al. (22), in a review of 12 papers between 1990 and 2018 where $84 \%$ of procedures were performed by thoracotomy, $13 \%$ by sternotomy, $3 \%$ by clamshell approach and only $1 \%$ by VATS.

In spite of the approach, pulmonary wedge resection is the most common procedure for metastasis excision with a percentage of about $77 \%$ in metastatic GCTs (22). This approach is preferred because allows parenchyma sparing, particularly useful when concomitant or future additional resections must be taken into account. Even more so since there is no evidence that anatomical resection improves outcomes over non-anatomical ones $(23,24)$.

Radicality of surgery (i.e., R0 resection) is strictly linked to survival in GCTs. Pfannschmidt et al. in 2010 (25), showed a survival improvement from $28.6 \%$ to $80.9 \%$ in patients with incomplete and complete resection and suggested that nodules until $0.3 \mathrm{~cm}$ should be removed $(19,21,26)$.

Usually, $0.5-1.0 \mathrm{~cm}$ is considered the optimal margin (27) for metastasectomy, however some authors have suggested wider normal lung tissue surrounding the nodule $(2,28)$. These criteria should be applied also for GCTs.

Lastly, nodal dissection role is still uncertain, but many series reported cases of mediastinal nodes involvement, suggesting that removal should be always considered $(12,22,29,30)$.

PM for GCTs is safe with low morbidity and 30 days mortality ranging from $0.0 \%$ to $3.6 \%(10,23,25)$. These data are consistent with PM in general. However, GCT patients are more likely to develop complications, since surgery is performed at the end of a chemotherapy regimen. In particular, since some regimens present higher lung toxicity, pulmonary complications are frequent. The most common pulmonary complications are ARDS, pneumonia, prolonged air leaks and prolonged respiratory failure requiring mechanical ventilation. Non-pulmonary complications are atrial fibrillation, sepsis and acute kidney failure.

Therefore, it is recommended to manage chemotherapy with a view to following surgery. In particular, patients treated with bleomycin seem to be more likely to develop respiratory complications due to lung toxicity $(31,32)$. Therefore, currently regimens consisting of etoposide, ifosfamide and cisplatin (VIP) are preferred to historical combination of bleomycin, etoposide and cisplatin (BEP) (33).

PM for GCTs is successful if part of a multidisciplinary approach based on chemotherapy as first treatment. According to recent literature, 5 years overall survival after $\mathrm{PM}$ ranges between $73 \%$ and $94 \%(10,12,25,30)$ with a median survival of 5.6 years in case of salvage surgery (23). These data confirm the significant improvement obtained with multimodal therapy over previous decades when survival ranged between $59 \%$ and $82 \%$.

To conclude, multimodal management is mandatory and PM for residual pulmonary disease after chemotherapy should be always considered. R0 must be achieved. 
Prognosis is determined by histology; if nodules resected result necrosis, fibrosis or mature teratoma, outcomes are favorable. On the contrary, when residual malignant cells are detected, outcomes worsen. Unfortunately, definitive diagnosis of necrosis, teratoma or viable cancer in lung nodules can be obtained only by pathology. Lastly, salvage surgery might have a role since it could prolong survival, despite being associated with ultimate adverse prognosis $(10,25,30)$.

\section{Non-surgical management}

SABR, stereotactic ablative radiotherapy, is an emerging treatment for pulmonary tumors. One of the most intriguing topics in these years is its role in the management of stage I NSCLC. At the moment, based on encouraging outcomes, it is common opinion that SABR is an established option in patients who refuse or are not fitting for surgery (34). In the same way, many authors support its attractiveness for the treatment of pulmonary oligo-metastases (35).

The role of SABR in oligo-metastatic patients is to achieve complete or partial tumor control due to its established efficacy with low side-effects incidence. Many papers report 1-year disease local control ranging between $70 \%$ and $95 \%$ of cases $(35-38)$. At the same time, some prognostic factors have been identified. Among these, the most influencing outcomes are number of metastases, size of pulmonary nodules, number of organs involved and duration of disease interval free period.

All published series concerning SABR in oligo-metastatic patients include different epithelial tumors and no evidence support that histology could be a significant prognostic factor $(39,40)$. Numbers of nodules, tumor dimension and DFI are the only prognostic factors with an evidence. It has been shown that prognosis is better when nodules are $5 \mathrm{~cm}$ or less and smaller than $3.3 \mathrm{~cm}$ in size, and DFI is longer than 3 years.

Evaluating the role of SABR in pulmonary germ cell tumors metastasis, the only available data come from previous retrospective trials without tumor specificity and based on heterogeneous groups of primary malignancies. Moreover, despite encouraging results, there are no prospective trials or retrospective large series with longterm follow-up supporting any evidences in favor of SABR versus surgery.

Therefore, also in the management of germ cell tumors metastasizing to the lungs, SABR should be alternative to surgery when lung resection is not feasible. SABR should also follows the same selection criteria adopted for surgery.

\section{Prostate cancer}

Prostate cancer is the most frequent male malignancy in Europe with an incidence of about 200 cases every 1,000 men (41). Primary and secondary preventions have significantly improved prognosis and decreased metastases incidence. However, 6.7/100,000 cases have advanced disease at diagnosis (42). Otherwise, metastases could present later as metachronous recurrences despite controlled primary disease $(43,44)$.

Metastases usually involve bone, bone marrow and regional nodes; visceral involvement is rare, about $15 \%$ of metastatic patients present lesions in liver, lungs, pleura, kidney and brain. Surprisingly, lung metastases are more frequent in autopsy than in advanced cases $(25 \%$ versus $5.7 \%$ ) (45). Unfortunately, visceral metastases are related to poor overall and disease-specific survival (42) compared to nodal and skeletal metastases (16 and 26 versus 43 and 61, 24 and 32 months respectively). Moreover, visceral metastases are rarely solitary $(0.3 \%)$, since often present with contemporary bone or nodal involvement (46).

As in GCTs, oligo-metastases or oligo-recurrences are probably an intermediate state of disease progression, strictly correlated with the development and dissemination of other future distant metastases. Saitoh (46) has reported this theory in a paper that proposed two models in which (I) every metastasis originates from primary tumor or (II) metastases originate from other metastases. According to the second theory, their removal could stop the natural disease progression to very advanced and disseminate stage.

\section{Surgery}

At present, the gold standard of care for metastatic prostate cancer is hormonal deprivation by surgical or chemical castration, also named systemic androgen deprivation therapy (ADT) $(47,48)$. Unfortunately, ADT is not curative but palliative and is generally continued until progression of the disease determining a cumulative toxicity over the years. Moreover, systemic therapy is often affected by many severe side effects such as sexual deficiency, bone fractures, anemia, vasomotor effects and cardiovascular injury.

Oligo-metastatic patients with visceral metastases could have different biological behavior and better prognosis 
compared to other metastatic subgroups. Therefore, in selected cases, surgical metastasectomy might result in long-term survival and avoid ADT with its side effects. Main criteria for prostate cancer PM are consistent with general metastasectomy. They include control of the primary cancer, R0 achievement, no extra thoracic disease and cardiopulmonary function suitable for surgery. Consequently, preoperative staging became determinant to confirm that criteria have been met. Technetium-99 bone scan and whole-body CT scan have been used until the advent of choline PET scan. Correct staging combined with meticulous follow up, allows to effectively identifying this subgroup of patients $(49,50)$.

Concerning optimal surgical approach, there are no evidences specific for prostate pulmonary metastases and criteria reported above for general and GCTs metastasectomy are reasonably applicable as well.

Literature about surgical treatment for pulmonary oligo-metastases in prostate cancer is poor and limited to case reports. Yao et al. (51), in their 2014 review, were able to find 4 cases of solitary prostate metastases treated by PM (52-55). Wallis et al. (56) have also cited these cases in a paper presenting also their single patient experience. They also cited some cases of multiple lung metastases without extra thoracic disease. These cases consisted of multi nodular, interstitial, endobronchial or pleural disease. Among them, just 3 cases obtained advantages by a combination of systemic and surgical therapy.

We have found two other recent cases of single pulmonary nodule surgically treated and resulting in postoperative undetectable PSA. The first one described by Rush et al. (57) in 2017 and the second by Mortier et al. in 2016 (58).

All the other cases reported in literature, despite oligometastatic state and PM, resulted in partial or absence of success as confirmed by increasing PSA and short survival $(59,60)$.

It is common opinion that postoperative PSA decreasing to undetectable level is the prognostic factor for prolonged survival. Otherwise, it is logical to think that other sites of disease have been left undetected.

Reasonably, the few successful cases were those true oligo-metastatic and that is why surgery was able to alter natural history of the disease. Whereas, cases with undetected disseminated disease develop new metastases shortly after diagnosis. Unfortunately, according to many authors, incidence of recurrence after PM is high and ranges between $21 \%$ to $44.8 \%$ (61-63). However, the authors themselves do not discourage a re-operation. In fact, potential benefit arising from surgery in solitary pulmonary nodule or oligo-metastatic cases is potentially curative and moreover avoid or delay side effects of ADT.

\section{Non-surgical management}

\section{SABR}

Local treatment, as an alternative to surgery, is represented by targeted radiotherapy. It can be delivered by conventional EBRT or by SABR. They act differently and SABR is supposed to induce an immune response favoring better tumor control.

The most common sites of metastasis treated by SABR are bone and regional nodes, in accordance with metastatic pattern frequency. Therefore, the most of series reported in literature does not address pulmonary metastases management.

Solitary lung oligo recurrences treated by radiotherapy are currently anecdotal in literature. At present, guidelines such as those from the National Comprehensive Cancer Network (NCCN) do not recommend ablative radiotherapy for curative metastatic prostate cancer therapy and define radiotherapy just a palliation for symptomatic patients.

\section{Target therapy}

ADT is the gold standard systemic therapy for hormonally sensitive prostate cancer (HSPC), whereas chemotherapy is adopted only in castration resistant patients (CRPC). However, in the last decade's introduction of new generation therapies has improved QoL and even survival.

ADT may determine changes in prostate tumor cells, leading to castration resistance. Many recent trials have shown that combination with new generation therapies could delay resistance's onset and improve survival. These therapies target the metabolic tumor pathways and act on changes induced by ADT itself. The efficacy of new generation hormones, abiraterone and enzalutamide, has been showed by many prospective randomized trials, both in pre and post chemotherapy setting $(64,65)$. The AFFIRM trial (66), focused on the efficacy of enzalutamide post docetaxel, was able to show a progression free survival of 8.3 months against 5.4 months of placebo, at imaging founding. The COU-AA-301 (67) tested the efficacy of abiraterone in the same above conditions and found a progression free survival of 5.6 months (2.0 in placebo). Even higher rates of progression free survival (16.5 months) have been reported in PREVAIL trial $(68,69)$ that showed how enzalutamide successfully reduces the risk of radiographic progression, improves survival and delayed chemotherapy. 


\section{Conclusions}

At present, PM in Germ Cell Tumors and Prostate Cancer must be discussed in a multidisciplinary tumor board to provide a maximally "tailor-made" approach with an integrated approach consisting of systemic therapy or less invasive technique, such as term ablation or stereotactic radiotherapy.

\section{Acknowledgments}

Funding: None.

\section{Footnote}

Provenance and Peer Review: This article was commissioned by the Guest Editor (Khosro Hekmat) for the series "Pulmonary Metastases" published in Fournal of Thoracic Disease. The article has undergone external peer review.

Conflicts of Interest: The authors have completed the ICMJE uniform disclosure form (available at http://dx.doi. org/10.21037/jtd.2020.04.51). The series "Pulmonary Metastases" was commissioned by the editorial office without any funding or sponsorship. MC serves as an unpaid editorial board member of Fournal of Thoracic Disease from Mar 2020 to Feb 2022. The authors have no other conflicts of interest to declare.

Ethical Statement: The authors are accountable for all aspects of the work in ensuring that questions related to the accuracy or integrity of any part of the work are appropriately investigated and resolved.

Open Access Statement: This is an Open Access article distributed in accordance with the Creative Commons Attribution-NonCommercial-NoDerivs 4.0 International License (CC BY-NC-ND 4.0), which permits the noncommercial replication and distribution of the article with the strict proviso that no changes or edits are made and the original work is properly cited (including links to both the formal publication through the relevant DOI and the license). See: https://creativecommons.org/licenses/by-nc-nd/4.0/.

\section{References}

1. Weichselbaum RR, Hellman S. Oligometastases revisited. Nat Rev Clin Oncol 2011;8:378-82.

2. Pastorino U, Buyse M, Friedel G, et al. Long-term results of lung metastasectomy: prognostic analyses based on 5206 cases. J Thorac Cardiovasc Surg 1997;113:37-49.

3. Handy JR, Bremner RM, Crocenzi TS, et al. Expert Consensus Document on Pulmonary Metastasectomy. Ann Thorac Surg 2019;107:631-49.

4. Sharir S, Foster RS, Donohue JP, et al. What is the appropriate follow-up after treatment? Semin Urol Oncol 1996;14:45-53.

5. Ghazarian AA, Trabert B, Devesa SS, et al. Recent trends in the incidence of testicular germ cell tumors in the United States. Andrology 2015;3:13-8.

6. Steyerberg EW, Keizer HJ, Messemer JE, et al. Residual pulmonary masses after chemotherapy for metastatic nonseminomatous germ cell tumor. Prediction of histology. ReHiT Study Group. Cancer 1997;79:345-55.

7. Liu D, Abolhoda A, Burt ME, et al. Pulmonary metastasectomy for testicular germ cell tumors: a 28-year experience. Ann Thorac Surg 1998;66:1709-14.

8. Bosl GJ, Sheinfeld J, Bajorin DF, et al. Cancer of the testis. In: Devita V Jr, Hellman S, Rosenberg SA. editors. Cancer, Principles and practice of Oncology. 7th edition. Philadelphia: Lippincott Williams \& Wilkins, 2005.

9. Albany C, Adra N, Snavely AC, et al. Multidisciplinary clinic approach improves overall survival outcomes of patients with metastatic germ-cell tumors. Ann Oncol 2018;29:341-6.

10. Cagini L, Nicholson AG, Horwich A, et al. Thoracic metastasectomy for germ cell tumours: long term survival and prognostic factors. Ann Oncol 1998;9:1185-91.

11. Schnorrer M, Ondrus D, Vichova B, et al. Surgical treatment of pulmonary metastases in germ-cell testicular cancer patients--long-term results. Bratisl Lek Listy 2009;110:620-2.

12. Besse B, Grunenwald D, Fléchon A, et al. Nonseminomatous germ cell tumors: assessing the need for postchemotherapy contralateral pulmonary resection in patients with ipsilateral complete necrosis.. J Thorac Cardiovasc Surg 2009;137:448-52.

13. Krege S, Beyer J, Souchon R, et al. European consensus conference on diagnosis and treatment of germ cell cancer: a report of the second meeting of the European Germ Cell Cancer Consensus group (EGCCCG): part I. Eur Urol 2008;53:478-96.

14. Johnston MDPM. Treatment of metastatic cancers. In: Devita V Jr, Hellman S, Rosenberg SA. editors. Principles and practice of Oncology. 7th edition. Philadelphia: Lippincott Williams \& Wilkins, 2005.

15. Robert JH, Ambrogi V, Mermillod B, et al. Factors 
influencing long-term survival after lung metastasectomy. Ann Thorac Surg 1997;63:777-84.

16. Stewart JR, Carey JA, Merrill WH, et al. Twenty years' experience with pulmonary metastasectomy. Am Surg 1992;58:100-3.

17. Schirren J, Trainer S, Eberlein M, et al. The role of residual tumor resection in the management of nonseminomatous germ cell cancer of testicular origin. Thorac Cardiovasc Surg 2012;60:405-12.

18. Boffa DJ, Rusch VW. Surgical techniques for nonseminomatous germ cell tumors metastatic to the lung. Chest Surg Clin N Am 2002;12:739-48.

19. Tóth L, Bodrogi I, Baki M, et al. Thoracic surgery of testicular cancer patients. Eur J Surg Oncol 1993;19:609-13

20. Eckardt J, Licht PB. Thoracoscopic versus open pulmonary metastasectomy: a prospective, sequentially controlled study. Chest 2012;142:1598-602.

21. Margaritora S, Porziella V, D'Andrilli A, et al. Pulmonary metastases: can accurate radiological evaluation avoid thoracotomic approach? Eur J Cardiothorac Surg 2002;21:1111-4.

22. Farazdaghi A, Vaughn DJ, Singhal S. Pulmonary Metastasectomy for Germ Cell Tumors. Ann Thorac Cardiovasc Surg 2019;25:289-95.

23. Kesler KA, Wilson JL, Cosgrove JA, et al. Surgical salvage therapy for malignant intrathoracic metastases from nonseminomatous germ cell cancer of testicular origin: analysis of a single-institution experience. J Thorac Cardiovasc Surg 2005;130:408-15.

24. Lo Faso F, Solaini L, Lembo R, et al. Thoracoscopic lung metastasectomies: a 10-year, single-center experience. Surg Endosc 2013;27:1938-44.

25. Pfannschmidt J, Hoffmann H, Dienemann H. Thoracic metastasectomy for nonseminomatous germ cell tumors. J Thorac Oncol 2010;5:S182-6

26. Saisho S, Nakata M, Sawada S, et al. Evaluation of videoassisted thoracoscopic surgery for pulmonary metastases: 11-years of experience. Surg Endosc 2009;23:55-61.

27. Rusch VW. Pulmonary metastasectomy. Current indications. Chest 1995;107:322S-31S.

28. Martini N, McCormack PM. Evolution of the surgical management of pulmonary metastases. Chest Surg Clin N Am 1998;8:13-27.

29. McGuire MS, Rabbani F, Mohseni H,et al. The role of thoracotomy in managing postchemotherapy residual thoracic masses in patients with nonseminomatous germ cell tumours. BJU Int 2003;91:469-73.
30. Fizazi K, Tjulandin S, Salvioni R, et al.Viable malignant cells after primary chemotherapy for disseminated nonseminomatous germ cell tumors: prognostic factors and role of postsurgery chemotherapy--results from an international study group. J Clin Oncol 2001;19:2647-57

31. Andrade RS, Kesler KA, Wilson JL, et al. Short- and longterm outcomes after large pulmonary resection for germ cell tumors after bleomycin-combination chemotherapy. Ann Thorac Surg 2004;78:1224-8; discussion 1228-9.

32. Loehrer PJ Sr, Johnson D, Elson P, et al. Importance of bleomycin in favorable-prognosis disseminated germ cell tumors: an Eastern Cooperative Oncology Group trial. J Clin Oncol 1995;13:470-6.

33. Ranganath P, Kesler KA, Einhorn LH. Perioperative Morbidity and Mortality Associated With Bleomycin in Primary Mediastinal Nonseminomatous Germ Cell Tumor. J Clin Oncol 2016;34:4445-6.

34. Timmerman R, Paulus R, Galvin J, et al. Stereotactic body radiation therapy for inoperable early stage lung cancer. JAMA 2010;303:1070-6.

35. Rusthoven KE, Kavanagh BD, Burri SH, et al. Multiinstitutional phase I/II trial of stereotactic body radiation therapy for lung metastases. J Clin Oncol 2009;27:1579-84.

36. Norihisa Y, Nagata Y, Takayama K, et al. Stereotactic body radiotherapy for oligometastatic lung tumors. Int J Radiat Oncol Biol Phys 2008;72:398-403.

37. Ricardi U, Filippi AR, Guarneri A, et al. Stereotactic body radiation therapy for lung metastases. Lung Cancer 2012;75:77-81.

38. Okunieff P, Petersen AL, Philip A, et al. Stereotactic Body Radiation Therapy (SBRT) for lung metastases. Acta Oncol 2006;45:808-17.

39. Milano MT, Katz AW, Zhang H, et al. Oligometastases treated with stereotactic body radiotherapy: long-term follow-up of prospective study. Int J Radiat Oncol Biol Phys 2012;83:878-86.

40. Milano MT, Katz AW, Muhs AG, et al. A prospective pilot study of curative-intent stereotactic body radiation therapy in patients with 5 or fewer oligometastatic lesions. Cancer 2008;112:650-8.

41. Heidenreich A, Bastian PJ, Bellmunt J, et al; EAU guidelines on prostate cancer. part 1: screening, diagnosis, and local treatment with curative intentupdate 2013. European Association of Urology. Eur Urol 2014;65:124-37.

42. Gandaglia G, Karakiewicz PI, Briganti A, et al. Impact of the Site of Metastases on Survival in Patients with 
Metastatic Prostate Cancer. Eur Urol 2015;68:325-34.

43. Niibe Y, Chang JY. Novel insights of oligometastases and oligo-recurrence and review of the literature. Pulm Med 2012;2012:261096.

44. Niibe Y, Jingu K, Onishi H. Oligo-recurrence and Syncoligometastases. J Thorac Oncol 2018;13:e59-60.

45. Bolton BH. Pulmonary metastases from carcinoma of the prostate: incidence and case report of long remission. J Urol 1965;94:73-7.

46. Saitoh H, Hida M, Shimbo T, et al. Metastatic patterns of prostatic cancer. Correlation between sites and number of organs involved. Cancer 1984;54:3078-84.

47. Cornford P, Bellmunt J, Bolla M, et al. EAU-ESTROSIOG Guidelines on Prostate Cancer. Part II: Treatment of Relapsing, Metastatic, and Castration-Resistant Prostate Cancer. Eur Urol 2017;71:630-42.

48. Pagliarulo V, Bracarda S, Eisenberger MA, et al. Contemporary role of androgen deprivation therapy for prostate cancer. Eur Urol 2012;61:11-25.

49. Picchio M, Briganti A, Fanti S, et al. The role of choline positron emission tomography/computed tomography in the management of patients with prostate-specific antigen progression after radical treatment of prostate cancer. Eur Urol 2011;59:51-60.

50. Lee ST, Lawrentschuk N, Scott AM. PET in prostate and bladder tumors. Semin Nucl Med 2012;42:231-46.

51. Yao HH, Hong MKh, Corcoran NM, et al. Advances in local and ablative treatment of oligometastasis in prostate cancer. Asia Pac J Clin Oncol 2014;10:308-21.

52. Chao DH, Higgins JP, Brooks JD. Biochemical remission after resection of prostate cancer lung metastasis. Urology 2004;63:584-5.

53. Pepe P, Fraggetta F, Tornabene F, et al. Solitary lung metastasis after radical prostatectomy in presence of undetectable PSA. Arch Ital Urol Androl 2012;84:208-10.

54. Goto T, Maeshima A, Oyamada Y, et al. Solitary pulmonary metastasis from prostate sarcomatoid cancer. World J Surg Oncol 2010;8:101.

55. Pruthi RS, Hubbard JS, Kouba E, et al. Androgenindependent prostate cancer treated with resection of the solitary metastatic site. Urol Int 2007;79:371-3.

56. Wallis CJ, English JC, Goldenberg SL. The role of resection of pulmonary metastases from prostate cancer: a case report and literature review. Can Urol Assoc J 2011;5:E104-8.

57. Rush J, Pai R, Parikh RA. Complete biochemical response after pulmonary metastasectomy in prostate adenocarcinoma.. Exp Hematol Oncol 2017;6:25.

58. Mortier D, Baten E, Vandeurzen K, et al. The Benefit of a Surgical Resection of a Solitary Pulmonary Metastasis of Prostate Cancer after Radical Prostatectomy. Curr Urol 2017;10:210-2.

59. Boyer BP, Boyer MJ. An elusive tumor in a man who has evidence of prostate cancer metastasis. JAAPA 2009;22:22, 24-5.

60. Hofland CA, Bagg MD. An isolated pulmonary metastasis in prostate cancer. Mil Med 2000;165:973-4.

61. Laisaar T, Vooder T, Umbleja T. Thoracoscopic resection of a solitary pulmonary nodule in patients with a known history of malignancy. Thorac Cardiovasc Surg 2008;56:418-21.

62. Rena O, Papalia E, Oliaro A, et al. Pulmonary metastases from epithelial tumours: late results of surgical treatment. Eur J Cardiothorac Surg 2006;30:217-22.

63. Saito Y, Omiya H, Kohno K, et al. Pulmonary metastasectomy for 165 patients with colorectal carcinoma: A prognostic assessment. J Thorac Cardiovasc Surg 2002;124:1007-13.

64. Ryan CJ, Smith MR, de Bono JS, et al. Abiraterone in Metastatic Prostate Cancer without Previous Chemotherapy. N Engl J Med 2013;368:138-48.

65. Rathkopf DE, Smith MR, De Bono JS, et al. Updated interim efficacy analysis and long-term safety of abiraterone acetate in metastatic castration-resistant prostate cancer patients without prior chemotherapy (COU-AA-302). Eur Urol 2014;66:815-25.

66. de Bono JS, Logothetis CJ, Molina A, et al. Abiraterone and increased survival in metastatic prostate cancer. $\mathrm{N}$ Engl J Med 2011;364:1995-2005.

67. Scher HI, Fizazi K, Saad F, et al. Increased survival with enzalutamide in prostate cancer after chemotherapy. $\mathrm{N}$ Engl J Med 2012;367:1187-97.

68. Fizazi K, Scher HI, Molina A, et al. Abiraterone acetate for treatment of metastatic castration-resistant prostate cancer: final overall survival analysis of the COU-AA- 301 randomised, double-blind, placebo-controlled phase 3 study. Lancet Oncol 2012;13:983-92.

69. Beer TM, Armstrong AJ, Rathkopf DE, et al. Enzalutamide in metastatic prostate cancer before chemotherapy. N Engl J Med 2014;371:424-33.

Cite this article as: Raveglia F, Rosso L, Nosotti M, Cardillo G, Scarci M. Pulmonary metastasectomy in germ cell tumors and prostate cancer. J Thorac Dis 2021;13(4):2661-2668. doi: $10.21037 /$ jtd.2020.04.51 